\title{
CITRA HOTEL TUGU MALANG DI MATA NETIZEN (Resepsi Terhadap Vlog "Experience Menginap Di Hotel Ter-antik Di Malang”)
}

\author{
Rimalinda Lukitasari \\ Email: rimatanzil@gmail.com \\ POLITEKNIK INTERNASIONAL BALI
}

\begin{abstract}
The image of a hotel in the eye of the society can sometimes not be in line with the identity concept that is trying to be communicated by the company. Hotel Tugu Malang is one of the hotel in Indonesia which has a strong heritage concept, but the image that is developing in the society has much distorted into an ancient and spooky direction. This study on the vlog entitled "Experience Menginap di Hotel Ter-antik di Malang" by YouTuber Anak Kuliner is aiming to become a form of evaluation to the public relation strategy by analysing the audience reception to the message in the vlog.

The research was conducted with a qualitative-descriptive method by using the theory of reception. The results show that despite the informative, cheerful, bright, positive, friendly, and enthusiastic contents nuance, the audience receptions still largely stand in the opposition position, with some started to move to the negotiation position and dominant hegemonic position. Therefore, it is suggested that the management continues to do positive publicity efforts which are integrating different media types and maximizing the use of storytelling.
\end{abstract}

Keywords: Image, Heritage, Tugu Malang Hotel, Netizen

\begin{abstract}
ABSTRAK
Citra suatu hotel di mata masyarakat kadang kala dapat tidak sejalan dengan konsep identitas yang ingin dikomunikasikan oleh perusahaan. Hotel Tugu Malang merupakan salah satu hotel di Indonesia yang kental akan unsur heritage, namun citra yang berkembang di masyarakat banyak terdistorsi ke arah stigma kuno yang seram. Penelitian terhadap vlog berjudul "Experience Menginap di Hotel Ter-antik di Malang" oleh youtuber Anak Kuliner ini bertujuan untuk menjadi salah satu bentuk evaluasi terhadap strategi public relation Hotel Tugu Malang dengan cara menganalisis resepsi penonton terhadap pesan yang disampaikan dalam vlog.
\end{abstract}


Penelitian dilakukan dengan metode kualitatif-deskriptif dengan menggunakan teori resepsi. Hasil penelitian menunjukkan bahwa meskipun dengan nuansa konten yang informatif, ceria, cerah, positif, bersahabat, dan antusias, resepsi penonton masih banyak yang berada di posisi oposisi, dengan beberapa sudah mulai bergerak ke posisi negosiasi dan dominan hegemonik. Oleh karenanya, disarankan agar manajemen terus melakukan usaha publisitas positif yang mengintegrasikan beberapa jenis media yang berbeda dan memaksimalkan pemanfaatan metode storytelling.

Kata Kunci: Citra, Heritage, Hotel Tugu Malang, Netizen

\section{Pendahuluan}

Dalam persaingan industri parwisata yang ketat, diferensiasi merupakan suatu keniscayaan yang harus disadari oleh para pelaku usaha. Salah satu diferensiasi yang mampu menanamkan pengalaman unik yang meninggalkan kesan mendalam sehingga para wisatawan tersebut akan menceritakan pengalamannya kepada teman dan sanak saudara di negara asalnya, bahkan menimbulkan keinginan untuk kembali berkunjung merupakan budaya dan warisan budaya atau heritage. Mengeksplorasi budaya dapat menjadikan suatu tempat menjadi unik dan berbeda dari tempat lainnya. Hal ini dikarenakan tidak ada kebudayaan di dunia yang seratus persen sama antara satu dengan lainnya.

Penelitian Fernandes dan Rachao (2014) menunjukkan bahwa unsur pengetahuan dan pengalaman sangat penting bagi wisatawan heritage. Bentuk-bentuk otentisitas budaya lokal sebagai daya tarik sangat berhubungan dengan pengalaman wisatawan, dan sangat diapresiasi positif oleh wisatawan mancanegara, bahkan di skala industri perhotelan (Bestari, Suryawardani, dan Suryawan, 2020). Pengalaman wisatawan dapat dikelola dalam tiga fase, yaitu fase pre-experience, experience, dan post experience. Faktor pre-experience dapat dikatakan memegang peranan yang cukup penting, sebab pada fase ini ekspektasi pengunjung terhadap pengalaman yang akan dialaminya saat menggunakan produk akan 
terbentuk. Pada fase ini pengunjung mendapatkan gambaran umum awal tentang apa yang akan didapatkannya, dan hal ini secara langsung maupun tidak langsung akan mempengaruhi fase experience maupun postexperience (Pijls, Schreiber, dan Marle, 2011)

Kini, dengan adanya kemajuan teknologi komunikasi seperti media sosial, salah satunya Youtube, fase pre-experience dapat lebih mudah dibentuk. Eksposur merek dengan memanfaatkan Youtube dapat meningkatkan brand visibility dan juga berpengaruh terhadap brand preference (Kaldeen dan Hilal, 2019). Namun, Youtube sebagai sebuah media sosial juga dapat digunakan sebagai propaganda, seperti yang terjadi pada gerakan "Tourist Go Home" di Barcelona, yang dampak propagandanya terhadap pariwisata Barcelona semakin meluas karena kemunculan berbagai berita di Youtube berkaitan dengan gerakan tersebut (Karyotakis et.al, 2018). Hal ini menunjukkan bahwa promosi melalui Youtube, walaupun efektif dan mudah, juga harus dikelola dengan hatihati.

Grup Hotel Tugu merupakan salah satu hotel di Indonesia yang mengusung konsep heritage dengan menampilkan banyak unsur-unsur warisan budaya Indonesia dan Asia Tenggara. Empat properti grup Tugu mendapatkan certificate of excellent dari Tripadvisor karena secara konsisten terus mendapatkan ulasan yang baik dari pengunjung, serta dua diantaranya, yaitu Tugu Hotel Bali dan Hotel Tugu Lombok, memenangkan traveller's choice 2019 pada laman Tripadvisor (Tripadvisor a, 2019; Tripadvisor b, 2019; Tripadvisor c, 2019; Tripadivor d, 2019). Namun, disamping reputasi baik yang diraih oleh hotel tugu, kentalnya unsur heritage dalam konsep hotel nampaknya juga membawa citra negatif terhadap hotel di mata masyarakat. Secara khusus citra tersebut berkaitan dengan suasana seram, terutama pada Hotel Tugu 
Malang yang disebutkan oleh beberapa media amatir sebagai salah satu hotel angker di Indonesia.

Berbagai artikel berita tampak menampilkan foto seorang wanita berambut panjang, yang pernah dipajang di salah satu ruangan dalam hotel tersebut (Dream Muslim Lifestyle, 2018; Travellingyuk, 2016). Bahkan, jika kata kunci Hotel Tugu Malang diketikkan pada laman pencarian Google maka akan muncul saran pencarian "Hotel Tugu Malang Angker", maupun "Hotel Tugu Malang Seram" pada deretan saran pencarian tersebut. Kesan seram ini diduga karena banyaknya koleksi barang antik yang dipajang di properti Hotel Tugu, termasuk Hotel Tugu Malang. Kasus pada Hotel Tugu Malang ini merupakan salah satu contoh tidak mudahnya menjadikan unsur-unsur heritage sebagai suatu distinctive advantage.

Dalam sebuah audit terhadap startegi public relation Hotel Tugu Malang oleh Jayanti, Prasetyo, dan Kanto (2017) menunjukkan bahwa tingkat hunian Hotel Tugu Malang dari tahun 2012 hingga tahun 2016 terus menurun. Untuk mengatasi hal tersebut, diutarakan perlunya sebuah perbaikan atau pembaharuan terhadap citra merek Hotel Tugu Malang. Salah satu permasalahan yang disoroti adalah mengenai citra Hotel Tugu Malang yang diasosiasikan dengan stigma seram. Untuk mengatasi hal ini, penelitian tersebut, diantaranya, menyarankan penyusun pesan komunikasi visual yang lebih berwarna-warni dan menonjolkan kesan elegan dan romantis untuk menepis kesan seram tersebut. Disebutkan pula perlunya menjalin hubungan erat dengan media dan influencer berpengaruh untuk membantu penyebaran pesan promosi yang lebih positif.

Pada satu sisi, keunikan Hotel Tugu membawa pada kesan kemewahan namun di lain sisi membawa pada munculnya stigma negatif terhadap hotel yang bersangkutan. Penelitian ini bertujuan untuk mengevaluasi kembali apakah strategi komunikasi public relation yang dijalankan sudah mampu menggeser stigma seram yang disandang Hotel 
Tugu Malang di tengah masyarakat atau belum. Untuk mengetahui hal tersebut, digunakan penelusuran resepsi penonton terhadap salah satu vlog ulasan di Youtube yang berjudul "Experience Menginap di Hotel Ter-antik di Malang” oleh youtuber Anak Kuliner (2018).

\section{Konsep dan Teori}

Konsep yang akan dijelaskan adalah mengenai Citra Hotel Tugu Malang di Mata Netizen, dan Resepsi terhadap vlog "Experience Menginap di Hotel Ter-antik di Malang” oleh youtuber Anak Kuliner.

\subsection{Citra Hotel Tugu Malang di Mata Netizen}

Dalam hal produk, citra atau image adalah satu set asosiasi yang diartikan atau dilihat oleh audiens terhadap suatu produk atau merek, dan berbagai citra ini dapat digunakan sebagai pertimbangan dalam membentuk brand identity (Aaker, 1996: 71). Citra merek merupakan representasi suatu merek dipikiran konsumen yang timbul dari pengalaman yang dialaminya (de Mooij, 2010: 25), termasuk berbagai macam rekam jejak yang juga dapat disebabkan oleh emosi dan asosiasi simbolik yang ditimbulkan oleh merek tersebut (Anandan, 2009: 131)

Hotel Tugu Malang merupakan salah satu properti milik Grup Tugu Hotel yang memang dikenal mengusung konsep-konsep heritage Indonesia dan Asia Tenggara. Dengan tagline the Arts, Soul, and Romance of Indonesia, konsep heritage pada Hotel Tugu tercermin dalam bentuk produk tangible dan intangible-nya, misalnya dengan adanya arca, tempat tidur kuno, bentuk aksesoris interior yang terkesan antik, serta foto dan lukisan bersejarah; sajian kuliner khas Indonesia, Asia Tenggara, dan Peranakan; sampai pada perancangan produk pelayanan yang mengusung tema warisan budaya Indonesia seperti adanya event Indonesian Cultural Dinning Series yang bukan saja menyajikan makanan khas Indonesia 
namun juga menampilkan pertunjukkan seni khas Indonesia seperti diantaranya wayang orang dan angklung (Tugu Hotels, 2020).

Konsep heritage dengan menampilkan barang antik dan bersejarah tersebut merupakan identitas yang ingin disampaikan oleh Hotel Tugu, sedangkan impresi masyarakat terhadap Hotel Tugu yang menampilkan hal-hal yang bersifat heritage inilah yang diartikan sebagai citra. Konsep Citra Hotel Tugu Malang yang dimaksudkan di sini adalah gambaran atau impresi masyarakat sebagai audiens terhadap Hotel Tugu Malang yang berkaitan dengan unsur-unsur budaya yang diturunkan dari para pendahulu dan masih memiliki nilai sejarah yang penting. Audiens yang dibahas di sini adalah audiens pada ranah komunikasi internet atau netizen yang dapat diartikan sebagai pengguna internet yang berkomunikasi secara aktif melalui media internet (Romli, 2018: 180).

2.2 Resepsi terhadap Vlog "Experience Menginap di Hotel Terantik di Malang" oleh youtuber Anak Kuliner

Resepsi merupakan suatu proses penciptaan makna antara penonton dan media yang ditonton (Eichner, 2014: 67). Dalam resepsi, sentral penelitian adalah pada pembaca, atau penerima pesan, sebagai pihak yang mengintepretasikan makna (Fourie, 2006: 244). Pemaknaan pesan tersebut dapat dipengaruhi oleh lingkungan dan pengalaman masa lalu yang dialami oleh penerima pesan (Ott dan Mack, 2020: 260).

Kata $v \log$ sendiri tidak jelas kapan pertama kali digunakan. Beberapa literatur menjelaskan vlog sebagai gabungan dari kata video dan log, maupun video dan blog. Keduanya mengacu pada catatan harian yang disampaikan melalui media vidio dan diunggah ke internet untuk dilihat orang lain (Kindarto, 2008: 184; Corbuzier, 2018: 94). Vlog "Experience Menginap di Hotel Terantik di Malang” merupakan sebuah konten video pengalaman yang diunggah ke media sosial Youtube oleh seorang youtuber - sebutan untuk orang yang memiliki channel di Youtube - yang 
menggunakan nama akun Anak Kuliner. Video ini sendiri berisi pengalaman Anak Kuliner ketika sedang menginap di Hotel Tugu Malang. Video ini menunjukkan sisi-sisi heritage Hotel Tugu Malang yang disebut dengan istilah "terantik" dengan menampilkan bagian dalam hotel termasuk kamarnya, kemudian tur keliling hotel yang dipandu salah seorang staf hotel, dan diakhiri dengan video ulasan makanan. Berbagai komentar yang diunggah pada kolom komentar video ini diteliti sebagai resepsi penonton dan menjadi studi kasus untuk melihat citra Hotel Tugu Malang di Mata Netizen.

\subsection{Teori}

Penelitian ini menggunakan teori resepsi untuk menganalisis beberapa komentar netizen terhadap video blog "Experience menginap di hotel terantik di Malang" yang berkaitan dengan citra Hotel Tugu Malang. Proses pengiriman dan penerimaan pesan melalui suatu proses penyusunan kode (encoding) dan penyingkapan kode (decoding). Kedua proses tersebut dipengaruhi oleh kode-kode yang sudah dipahami oleh masingmasing partisipan. Namun, pada proses decoding makna yang diinginkan untuk disampaikan oleh pemberi pesan dalam tahap encoding tidak selalu dimaknai seperti yang diinginkan (Hall, 1999).

Hall (1999: 515-517) menjelaskan bahwa penerima pesan dapat berada pada salah satu dari tiga posisi dalam menjalani proses decoding, yaitu posisi dominan-hegemonik, posisi negosiasi, dan posisi oposisi. Pada posisi dominan-hegemonik, penyingkapan kode pesan yang yang diterima oleh penerima pesan sejalan dengan yang diinginkan oleh pengirim pesan. Hal ini terjadi karena baik pengirim pesan maupun peneriman pesan memahami konvensi yang sama dalam hal kode dominan yang digunakan. Posisi negosiasi terbentuk pada saat penerima pesan memahami kode dominan yang disampaikan dalam pesan, namun penerima pesan juga memiliki kode yang berlaku di lingkungannya. Pemahaman penerima 
pesan kemudian lebih condong mengikuti kode yang berlaku di lingkungannya serta dipengaruhi pula oleh situasi di sekitarnya. Posisi negosiasi berada diantara dominan-hegemonik dan oposisi. Pada posisi ini reaksi penerima pesan bertolak belakang dengan yang diharapkan oleh pemberi pesan. Reaksi berseberangan ini tidak selalu disebabkan oleh adanya ketidakpahaman mengenai kode yang sedang disampaikan, namun bisa saja terjadi karena penerima pesan memiliki kerangka berpikir alternatif yang dipengaruhi oleh situasi tertentu yang memberikan dasar dalam membuat interpretasi makna yang berbeda dengan yang disusun oleh pemberi pesan.

\section{Metode}

Penelitian ini menggunakan pendekatan kualitatif sebagai suatu metode untuk melihat pengalaman manusia melalui suatu set perangkat penelitian antara lain wawancara, observasi, studi konten, maupun studi kesejarahan seperti biografi (Hennink, Hutter, dan Bailey, 2020: 10). Secara lebih khusus, penelitian ini merupakan studi terhadap konten yang bersumber dari internet. Data primer bersumber dari konten vlog “Experience Menginap di Hotel Ter-antik di Malang” oleh youtuber Anak Kuliner, dan beberapa komentar netizen yang dituliskan pada kolom komentar $v \log$ tersebut. Data sekunder berupa artikel berita serta dokumendokumen yang lain. Teknik pengumpulan data yang digunakan dalam penelitian ini adalah teknik dokumenter, observasi, dan pencatatan. Analisis data pada penelitian terhadap resepsi netizen pada vlog "Experience Menginap di Hotel Ter-antik di Malang" dilakukan secara deskriptif-kualitatif dengan berpegang pada teori Resepsi. 


\section{Hasil dan Pembahasan}

Vlog dengan judul "Experience menginap di Hotel Ter-antik di Malang" adalah sebuah vidio blog ulasan yang diunggah oleh Anak Kuliner pada saluran Youtube-nya. Vidio yang diunggah pada 6 September 2018 ini berisi tentang ulasan Anak Kuliner terhadap pengalamannya menginap di Hotel Tugu Malang. Vidio ini telah ditonton sebanyak 90.491 kali dan terdapat 316 komentar dalam kolom komentar video. Anak Kuliner sendiri memiliki 743.000 subscriber di Youtube.

Pada konten vlog ulasan Anak Kuliner tersebut, tampak digunakan tanda-tanda yang diusahakan menjauh dari kesan seram. Beberapa tanda tersebut muncul dalam penggunaan kata-kata yang positif seperti "seru", "keren", "wow", "cantik", "fenomenal", dan "antik". Selain itu, terdapat pula penerapan musik latar yang ceria, dan raut wajah serta gestur tubuh yang tampak selalu tersenyum dan bersemangat.

Resepsi penonton dipilih dan direduksi menjadi beberapa kelompok komentar. Beberapa komentar yang dipilih adalah komentar yang menunjukkan respon terhadap isi video berkaitan dengan citra Hotel Tugu Malang. Dari beberapa komentar tersebut terlihat bahwa video ulasan tentang Hotel Tugu Malang ini menuai beberapa kelompok respon. Ada respon yang menunjukkan rasa seram, rasa kagum dan suka, rasa penasaran, penguatan akan sisi kesejarahan, dan ungkapan keragu-raguan akan citra hotel.

Dari berbagai komentar yang menunjukkan rasa seram, tampak bahwa kesan seram atau horor tersebut diantaranya disebabkan dari keberadaan foto Oei Hui Lan, banyaknya barang antik, penerapan warna merah pada interior, dan suasana yang redup. Rasa seram karena foto Oei Hui Lan ini bisa muncul dari pengaruh media yang selalu mengasosiasikan wanita berambut panjang dan berbaju putih sebagai sosok yang 
menyeramkan. Ditambah lagi foto tersebut adalah foto hitam putih yang terkesan kuno.

Suasana yang kuno dan antik tampaknya memang banyak membuat orang merasa seram, seperti tampak pada contoh kutipan berikut:

Eni Slestari : "Antik banget hotelnya, kayanya ngeri deh kalo tidur dsitu, brasa merinding, hahahahahaaa"

Niken A : "Bagus hotelnya. Tapiiiii horror bagi gue wkwk banyak barang antik \& foto orgnya hiiiii"

Sedangkan suasana redup dan penerapan warna merah juga diasosiasikan orang dengan sesuatu yang menyeramkan, seperti kutipan berikut:

Dian Urip Suci : "Bagus sih, elegan, classy tp lorong2 cat warna Heriyanti merahnya serem ya"

Iche Ocha : "Aura kamarnya redup2 gimana gitu ko ga horror kah?? Klo gw malamnya ga bisa tidur takut ada yg nemenin"

Beberapa komentar penonton tersebut dapat menunjukkan bahwa stigma seram pada Hotel Tugu Malang belum dapat sepenuhnya dihapuskan, walaupun video yang ditampilkan sudah tampak diarahkan kepada kesan ceria. Hal ini dapat dikarenakan stigma tersebut sudah terlanjur melekat. Dari komentar akun Hendy 02 Oke mengatakan "Horor bgt asli. Ini karna pagi dan musiknya ceria ...jadi kesan horornya gak gitu keliatan", dapat dilihat jika pengambilan gambar saat siang dan penerapan musik ceria memang bisa mengurangi kesan seram, namun tidak bisa sepenuhnya. Bahkan ada yang menganggap walaupun siang masih terlihat seram, seperti yang diungkapkan akun lia imoet yang menuliskan "Siang2 aja serem apa lg malam. Kl hotel2 daerah bgni y, wlpn dbilang bintang 5 kesan na serem: D”. 
Tanda-tanda yang tidak disengajapun bisa diresepsikan sebagai sesuatu yang menunjukkan hal-hal mistis bagi penonton, seperti beberapa contoh kutipan berikut:

Runny Botax : "Pas diruangan koleksi owner hotel menit 14:35an kamera sering ngeblurr gitu ya?

Aura mistis di hotel ini huhuuyyyy kayanya"

Khanza Mommy : "Pas di waroeng shanghai beberapa $\mathrm{x}$ kamera ngebrur... pasti banyak cesper nya"

Pada komentar-komentar di atas tampak kondisi kamera yang tibatiba tidak fokus dianggap sebagai suatu tanda adanya energi mistis. Tampak akun Khanza Mommy menghubungkannya dengan kehadiran cesper (=Casper), yang merupakan tokoh fiksi kartun berupa hantu yang baik hati.

Diantara komentar-komentar yang secara tegas mengatakan bahwa Hotel Tugu Malang seram, walaupun setelah menonton video yang dikemas ceria, terdapat komentar-komentar yang masih menunjukkan keragu-raguan dan bahkan masih menunjukkan perlu adanya penegasan lebih lanjut, seperti tampak pada beberapa komentar berikut:

Edward Chang : : "Serem ga hotelnya?"

Princess Firda : "Hotel tugu aman aja kan yaa.. Gak angker? Pengen nyoba kesana sih, aku Cuma pernah ke royal angkornya aja di hotel tugu. Keren khas Thailand gitu"

M S Aja : "Review nya sampe pagi setelah nginep sana donk. Kesan nya gimana? Ada serem2 nya ngak malem2 gitu?"

Tampak pada komentar akun $M S$ aja bahwa video yang diambil pada saat siang hari belum bisa meyakinkan bahwa hotel tersebut tidak seram seperti anggapan umum selama ini. Beberapa kutipan komentar tersebut juga menunjukkan bahwa komentar netizen juga dapat mempengaruhi keputusan pembelian calon pengunjung. Seperti tersirat 
dalam komentar Princess firda yang mencari penegasan terlebih dahulu sebelum memutuskan untuk menginap di Hotel Tugu Malang.

Selain resepsi penonton yang cenderung masih belum beranjak dari stigma negatif Hotel Tugu Malang, tentu saja terdapat juga resepsi yang bersifat positif, dan bahkan memberikan penguatan terhadap aspek heritage Hotel Tugu Malang. Ada penonton yang merasa bahwa kesan antik tersebut justru merupakan hal yang menarik dan bahkan suka walaupun kesannya sedikit seram, seperti komentar Alivia Adzhari yang mengatakan "Aesthetic banget sebenernya tp redup" gitu nuansanya jadi agak horror. Tapi gue suka sih yang antik" gitu”.

Ada pula resepsi yang menunjukkan persetujuan terhadap citra heritage Hotel Tugu Malang seperti komentar Ronald Trumph yang mengatakan "Sungguh luar biasa, no 2 nya hotel mojopahit Surabaya". Seperti diketahui, Hotel Majapahit di Surabaya adalah hotel dengan latar belakang sejarah yang kental. Dengan mengasosiasikan Hotel Tugu Malang kepada Hotel Majapahit tentunya penonton tersebut melihat citra Hotel Tugu Malang yang tampak dari video ulasan yang dibuat oleh Anak Kuliner tersebut sebagai hotel yang bersejarah ketimbang sebagai hotel yang seram.

Diantara komentar-komentar yang tertulis di kolom komentar video "Experience Menginap di Hotel Ter-antik di Malang" tersebut, ada komentar menarik yang bisa saja memberikan masukkan kepada pihak manajemen dalam mengelola citra Hotel Tugu Malang. Komentar itu tertulis seperti di bawah ini:

Cak Redi

"Walau kesannya horror, tapi anehnya bikin
betah. Kalau kamu pecinta seni atau literasi,
highly recommended. Tapi agak mahal sih ya,
secara kelas Gallery. Dibuat setting film bagus
nih, kaya The Grand Budapest Hotel etc."


Hal yang menarik dari komentar tersebut adalah tentang penyebutan judul film The Grand Budapest Hotel. Dari hal itu dapat dilihat bahwa penonton melihat Hotel Tugu Malang yang kesannya seram itu sebenarnya tidaklah seram, dan bahkan cocok digunakan sebagai latar film yang bertema komedi. The Grand Budapest Hotel adalah sebuah film yang berlatar sebuah hotel di tahun 1930an. Pada film, hotel yang menjadi latar tentu saja tampak kuno dan redup, namun tetap tidak menampakkan kesan seram, karena konteksnya adalah sebagai latar film komedi.

Terdapat pula komentar yang secara tegas menunjukkan rasa suka terhadap Hotel Tugu Malang yang ditampilkan dalam video ulasan Anak Kuliner, dan bahkan terdapat pergeseran cara pandang terhadap citra Hotel Tugu Malang, seperti komentar-komentar berikut:

$\begin{array}{lll}\text { Hendry Sinaga } & : & \text { "Keren hotelnya } \\ \text { Riska Fitria } & : & \begin{array}{l}\text { "Sbg hotelier itu hotel unik multi culture } \\ \text { sekaliiii. Love it" }\end{array} \\ \text { Mi minel } & : & \text { "Hotel sejuta sejarah.. keren.." } \\ \text { Galih wicaksono } & : & \begin{array}{l}\text { Kok malah banyak yg bilang horror? Padahal } \\ \text { bagus banget guys... }\end{array}\end{array}$

Resepsi-resepsi penonton yang telah dipaparkan di atas menunjukkan bahwa resepsi penonton terhadap vlog "Experience Menginap di Hotel Ter-antik di Malang” oleh Anak Kuliner sebagian besar masih berada pada posisi oposisi, serta beberapa berada di posisi negosiasi dan dominan hegemonik dengan pesan yang ingin disampaikan oleh video ulasan tersebut. Posisi oposisi yang masih cukup tinggi tampak pada masih banyaknya komentar yang tetap menganggap Hotel Tugu Malang seram walaupun video ulasan sudah dikemas sedemikian rupa agar terkesan ceria. Posisi oposisi tampak pada resepsi penonton yang masih menganggap pengambilan gambar pada siang hari, penggunaan kata-kata unik, antik, keren, seni, fenomenal, dan cantik, serta penerapan musik latar yang ceria tidak mempengaruhi responnya ketika menonton video tersebut. Terbukti 
dengan masih adanya penonton yang merasa takut menonton video tersebut.

Posisi negosiasi terbentuk pada resepsi penonton yang menyadari pengemasan video yang dibuat ceria, namun stigma yang diterimanya selama ini masih terlalu kuat, sehingga mengaburkan pesan-pesan ceria yang disampaikan oleh tanda-tanda dalam video. Sedangkan posisi dominan hegemonik terbentuk pada resepsi penonton yang melihat Hotel Tugu Malang sebagai suatu hotel bernuansa heritage dan unik, dan bahkan ada yang telah mengalami pergeseran stigma ke arah citra positif terhadap hotel tersebut.

Dengan melihat pada pesan yang ingin disampaikan oleh Anak Kuliner dalam vlognya, serta resepsi penonton terhadap video tersebut, tampak bahwa citra heritage Hotel Tugu Malang di mata netizen masih belum kuat. Tampak bahwa stigma seram yang sudah terlanjur kuat menyebar di masyarakat masih mempengaruhi pandangan masyarakat terhadap citra heritage yang ingin disampaikan oleh hotel tersebut. Hal ini tampak dipengaruhi oleh beberapa hal, diantaranya ada mitos umum yang sudah dipercayai masyarakat mengenai hal-hal yang bernuansa kuno dan antik dan penggambaran dalam media yang mengaitkan hal-hal tertentu pada hal yang mistis. Namun, tidak semua masyarakat beranggapan demikian. Terlihat ada juga masyarakat yang berpandangan bahwa Hotel Tugu Malang sebagai hotel berkelas yang penuh unsur heritage yang bernilai.

\section{Simpulan dan Rekomendasi}

Dari hasil pembahasan, dapat disimpulkan bahwa citra Hotel Tugu Malang di mata netizen masih beragam. Hal ini tampak dari resepsi penonton yang terlihat beragam pula. Walaupun posisi oposisi masih cukup besar, namun diantaranya telah menunjukkan resepsi yang bersifat 
negosiasi dan dominan hegemonik. Memang tidak semua netizen yang berkomentar di kolom komentar vlog Anak Kuliner adalah calon konsumen potensial bagi Hotel Tugu Malang, namun komentar-komentar yang beredar di internet merupakan suatu bentuk electronic word of mouth yang dapat mempengaruhi citra Hotel Tugu Malang. Hal ini tentunya perlu untuk terus dikendalikan agar tidak membawa dampak negatif terhadap citra Hotel Tugu Malang di masa mendatang.

Beberapa rekomendasi yang dapat diberikan kepada pihak manajemen Hotel Tugu Malang adalah dengan mempertimbangkan pembuatan bentuk-bentuk publikasi yang lebih beragam dan terintegrasi dalam menggeser citra kuno dan seram kepada citra heritage. Strategi yang memanfaatkan kekuatan storytelling dapat juga diutamakan, karena respon orang terhadap sesuatu bisa sangat dipengaruhi oleh cerita yang pernah didengarnya yang lambat laun menjadi sesuatu yang dipercayanya, seperti yang terjadi dalam hal mitos.

Netizen pada era industri 5.0 ini banyak memegang peranan dalam menciptakan citra negatif maupun positif. Tampak bahwa pendapat penonton tidak bisa dengan mudah dibelokkan, maka diperlukan perancangan pesan yang kuat dan sebisa mungkin berlawanan kutub dengan stigma yang ingin digeser. Contoh yang dapat diambil adalah dengan cara membuat film-film mini yang dapat dimuat ke media sosial yang isinya bermuatan komedi namun tetap elegan. Bisa saja konsep utamanya adalah mengangkat interaksi keseharian di dalam hotel yang bersifat kekeluargaan dan umum, dengan bumbu-bumbu komedi, hal ini agar Hotel Tugu Malang dapat memposisikan dirinya menjadi lebih dekat dengan masyarakat.

Bagi penelitian selanjutnya. Penelitian Citra Hotel Tugu Malang di Mata Netizen: Studi Kasus vlog "Experience Menginap di Hotel Terantik di Malang" ini masih jauh dari sempurna. Citra negatif yang 
berhubungan dengan stigma mistis suatu akomodasi wisata sangat sering ditemui pada praktek di lapangan, oleh karenanya diharapkan kedepannya dapat dilakukan penelitian-penelitian yang lebih komprehensif mengenai dampak citra negatif yang berhubungan dengan hal-hal yang dianggap seram ini dan strategi-strategi komprehensif yang dapat dilakukan oleh pihak industri untuk menghindari maupun menanggulangi hal ini.

\section{Daftar Pustaka}

Aaker, D.A. 1996. Buliding Strong Brands. New York: Free Press Anak Kuliner. 2018. "Experience Menginap di Hotel Ter-antik di Malang”, sumber URL: https://www.youtube.com/watch?

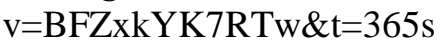

Anandan, C. 2009. Product Management. New Delhi: Tata McGraw-Hill Bestari, I P. Prasista, I. G.A. Oka Suryawardani, Agung Suryawan Wiranatha. 2020. Jurnal Kajian Bali. "Respons terhadap Otentisitas: Tanggapan Wisatawan Asing terhadap Unsur-unsur Budaya dalam Tiga Hotel Internasional di Bali”. Vol 10 no 01. P139 - 162

Corbuzier, D. 2018. Youtuber for Dummies. Jakarta: Buana Ilmu Populer de Mooij, M. 2010. Global Marketing \& Advertising: Understanding Cultural Paradoxes. Los Angeles: SAGE

Dream Muslim Lifestyle. 2018. "7 Hotel Angker dengan Kisah Mistis di Indonesia", sumber URL: https://travel.dream.co.id/destination/7hotel-angker-dengan-kisah-mistis-di-indonesia-180518p.html diakses 5 Januari 2020

Eichner, S. 2014. Agency and Media Reception: Experiencing Video Games, Film, and Television. Postdam: Springer

Fernandes, C, S. Rachao. 2014. "Reinventing tourism at a traditional cultural tourism destination: A case study of Viana do Castelo (Portugal)". International Journal of Business and Globalisation. Vol. 12, No. 3, p281 - 296.

Fourie, P.J (Ed). 2006. Media Studies: Content, Audience, and Production. Lansdowne: Juta Education

Hall, S. 1999. "Encoding, Decoding". Cultural Studies Reader. Second Edition. Simon During (ed). 507-517p. London: Routledge.

Hennink, M., I. Hutter, A. Bailey. 2020. Qualitative Research Methods (2 ${ }^{\text {nd }}$ ed). Los Angeles: SAGE

Jayanti, A.Y, B.D. Prasetyo, S. Kanto. 2017. "Strategic Communication Audit of Public Relations on Tugu Malang Hotel as Developing Company Image as One of Cultural Heritage Destination in 
Malang”. Asian Jurnal of Humanities and Social Studies. Vol. 05, No 05, p350 - 356

Kaldeen, M., MIM. Hilal. 2019. "Effect of Youtube Usage and Marketing Communication on Brand Preference". SEUSL Journal of Marketing. Vol. 4 No. 1. P 20 - 27

Karyotakis, M.A., N. Antonopoulos, A. Veglis., M. Kiourexidou. 2018. "Tourist Go Home: Communication and Propaganda on Youtube". Journal of Media Critique. Vol. 4 No. 14, p 323 - 337

Kindarto, A. 2008. Belajar Sendiri Youtube. Jakarta: Media Elex Komputindo

Ott, B.L. R.L. Mack. 2020. Critical Media Studies: An Introduction (3 ${ }^{\text {rd }}$ ed). Hoboken: John Wiley \& Sons.

Pijls, R, G.H. Schreiber, R. S. F van Marie. 2011. "Capturing the Guest Experience in Hotels. Phase One: Theoretical Background and Development of the Guest Experience Scan". Conference paper EuroChrie. available from http://researchgate.net/publication/ 236295984_CAPTURING_THE_GUEST_EXPERIENCE_IN_H OTELS_PHASE_ONE_THEORETICAL_BACKGROUND_AN D_DEVELOPMENT_OF_THE_GUEST_EXPERIENCE_SCA $\mathrm{N}$ [cited 26 May 2020]

Romli, A.S.M. 2018. Jurnalistik Online: Panduan Mengelola Media Online. Bandung: Nuansa Cendekia

Traveling yuk. 2016. "Bikin Merinding ternyata Hotel-hotel di Malang ini Dikenal Horor dan Angker", sumber URL: https://travelingyuk.com/hotel-angker-di-malang/22427?utm_ source=idle\&utm_medium=dekstop\&utm_campaign=reload diakses 5 januari 2020

Tripadvisor a. "Hotel Tugu Bali", sumber URL: https://www.tripadvisor. com/Hotel_Review-g311298-d304280-Reviews-Hotel_Tugu_ Bali-Canggu North Kuta Bali.ht'ml diakses 25 Mei 2020

Tripadvisor b. "Hotel Tugu Malang", sumber URL https://www. tripadvisor.com/Hotel_Review-g297710-d307824-ReviewsHotel_Tugu_Malang-Malang_East_Java_Java.html diakses 25 Mei 2020

Tripadvisor c. "Hotel Tugu Lombok", sumber URL: https://www. tripadvisor.com/Hotel_Review-g297733-d1167397-ReviewsHotel_Tugu_Lombok-Lombok_West_Nusa_Tenggara.html diakses 25 Mei 2020

Tripadvisor d. "Hotel Tugu Blitar", sumber URL: https://www. tripadvisor.com/Hotel_Review-g673462-d671663-Reviews-Hotel _Tugu_Blitar-Blitar_East_Java_Java.html diakses 25 Mei 2020

Tugu Hotels. http://tuguhotels.com/hotels/malang/accommodations/ diakses 30 Mei 2020 


\section{Profil Penulis}

Rimalinda Lukitasari menyelesaikan pendidikan strata satu Sastra Inggris dan strata dua Kajian Pariwisata di Universitas Udayana. Saat ini penulis merupakan dosen di Politeknik Internasional Bali. Ranah penelitian yang menjadi minat penulis adalah di bidang sastra dan pariwisata, serta komunikasi pemasaran, terutama pada penerapan storytelling pada promosi pemasaran pariwisata. 